\title{
FATORES QUE INTERFEREM NA
}

\section{IMPLANTAÇÃO DE UM MODELO DE \\ GESTÃO ESTRATÉGICA BASEADO NO}

\author{
BALANCED SCORECARD：ESTUDO DE
}

\section{CASO EM UMA INSTITUIÇÃO PÚBLICA}

FACTORS THAT INTERFERE IN THE IMPLANTATION OF A STRATEGIC MANAGEMENT MODEL BASED IN BALANCED SCORECARD: A STUDY CASE IN A PUBLIC INSTITUTION

\section{SÉRGIO HENRIQUE ARRUdA CAVALCANTE FORTE}

Professor Titular e Coordenador do Curso de Mestrado em Administração da UNIFOR Doutor e Mestre em Administração - FGV/EAESP Av. Washington Soares 1321, Bloco Q, Sala 3 - Fortaleza - CE - CEP 6081 1-905 


\section{RESUMO}

O Balanced Scorecard (BSC) é uma ferramenta empresarial que traduz a missão e a estratégia da organização em um conjunto de medidas de desempenho para propiciar a formação de uma estrutura de medição estratégica e de um sistema de gestão eficiente. Muitos fatores, entretanto, interferem na implantação de um instrumento gerencial desse porte, tanto em empresas privadas como em públicas. Objetivando identificar quais fatores interferiram na implantação de um Modelo de Gestão Estratégica (MGE) baseado no BSC em uma instituição governamental, realizou-se em 2003 uma pesquisa exploratória e descritiva por meio de um estudo de caso na Embrapa. Foram aplicados questionários aos gerentes do MGE de io das 40 Unidades da empresa. Identificou-se que diversos fatores interferem na implantação do BSC, destacando-se os relacionados aos gerentes nos diversos níveis. O grau de envolvimento e apoio da alta direção da organização foi considerado o principal fator para o sucesso na implantação de um instrumento de gestão como o BSC.

\section{PALAVRAS-CHAVE}

Balanced Scorecard; Barreiras à implantação do BSC; Estratégia.

\section{ABSTRACT}

The Balanced Scorecard (BSC) is a business tool that translates the mission and organization strategy in a group of performance measurements in order to create a strategic measurement structure and an efficient management system. Many factors nevertheless interfere in the implantation of a management instrument this size, as in private enterprises as in public ones. With the aim to identify which factors interfered in the implantation of a strategic management model based in BSC in a governmental institution, a exploratory and descriptive research was made in 2003 through a case study in Embrapa. Questionnaires were applied to the managers of strategic management model in ro of the 40 units of the enterprise. Many factors that interfere in the BSC implantation were identified, mainly the ones related to the many levels of managers. The involvement degree and support of the organization high direction were considered the main factor to the successful implantation of management instrument such as BSC. 


\section{KEYWORDS}

Balanced Scorecard; Barriers to BSC implementation; Strategic.

\section{INTRODUÇÃO}

De acordo com um estudo realizado pela empresa de consultoria Symnetics Business Transformation, em I999, com 30 empresas de médio e grande porte do Brasil, menos de Io\% das estratégias empresariais são eficientemente formuladas e executadas (RUAS, 2003), o que indica a existência de problema no processo de formulação ou de implantação das estratégias. O que se observa na literatura sobre planejamento estratégico é que a etapa de formulação de estratégia sempre foi muito estudada, enquanto que a implantação só recentemente está sendo considerada como uma etapa do processo de planejamento estratégico.

Uma análise das dez escolas de estudos de estratégia, apresentadas por Mintzberg, Ahlstrand e Lampel (2000), mostra isso. Da Escola do Design, onde se tem a formulação da estratégia como um processo de concepção, até a Escola de Configuração, em que a estratégia é vista como um processo de transformação, a ênfase é dada mais à formulação do que à implementação. Essa ênfase na formulação em detrimento da implementação da estratégia leva as empresas à desinformação do quanto da estratégia está sendo implementada e se as ações desenvolvidas estão efetivamente contribuindo para o alcance dos objetivos estratégicos das empresas e, conseqüentemente, para um bom desempenho empresarial.

Preocupados com a avaliação desse desempenho, o Instituto Nolan Norton, em I990, patrocinou um estudo em diversas empresas, visando a medir esse desempenho. Acreditava-se que os métodos de avaliação de desempenho empresarial, em geral apoiado por indicadores contábeis e financeiros, estavam obsoletos (KAPLAN; NORTON, I997). Desse estudo, surgiu o balanced scorecard (BSC).

Independente de como a estratégia da organização é formulada, ou seja, da escola de estratégia seguida pela organização, o BSC complementa o planejamento, pois "traduz a missão e as estratégias das empresas num conjunto abrangente de medidas de desempenho que serve de base para um sistema de medição e gestão estratégica" (KAPLAN; NORTON, I997:2), o que permite o acompanhamento e avaliação da implantação das estratégias.

Outro fator tem reforçado a necessidade da gestão estratégica: o aumento da importância dos ativos intangíveis. Durante a era industrial predominavam sistemas de controle financeiro cujo objetivo era facilitar e monitorar a alocação eficiente de capital físico e financeiro, ou seja, dos ativos tangíveis, para a obtenção de vantagens competitivas. Com o advento da era da informação, no entanto, a alocação eficiente desses ativos não é mais suficiente para obter e manter essa 
vantagem. A gestão dos ativos intangíveis se tornou mais decisiva para a competitividade das empresas do que a gestão dos ativos tangíveis.

Para as empresas do setor de serviço, onde os ativos intangíveis são os principais patrimônios, a gestão eficaz desses ativos é ainda mais importante. Isso é mais enfático para uma empresa de pesquisa científica, onde toda a sua produção depende desse patrimônio.

Kimura e Suen (2003:5) enfatizam a importância do BSC ao colocar que por meio dele é possível

[...] identificar a performance empresarial considerando os resultados de rentabilidade e custos, bem como os indicadores de atendimento das necessidades dos clientes, de eficiência de processos internos e de potencial de aprendizado e crescimento da empresa.

Preocupada com a eficácia de sua gestão, a Empresa Brasileira de Pesquisa Agropecuária (Embrapa) vem exercitando, desde I989, a elaboração e a execução do planejamento estratégico como instrumento de acompanhamento das mudanças do ambiente externo. O foco, mais uma vez, foi dado à formulação das estratégias em detrimento da implantação. Confirmando a estatística apresentada no início deste tópico, o processo de planejamento estratégico da Embrapa se mostrou deficiente na implantação das ações estratégicas (FRESNEDA, 2002).

Em busca de um instrumento que permitisse o alinhamento entre o Plano Diretor e as ações executadas, tanto em nível corporativo como para as Unidades da empresa, a Embrapa implantou um novo instrumento de gestão, baseado no balanced scorecard, chamado de Modelo de Gestão Estratégica (MGE). O MGE foi implantado com os objetivos de: traduzir a missão, visão e os objetivos da Embrapa em iniciativas e ações estratégicas; permitir a vinculação das metas institucionais previstas no Plano Diretor da Embrapa às metas das Unidades Descentralizadas, Unidades Centrais, equipes e pessoas; e criar indicadores para monitoramento contínuo do desempenho da empresa (EMBRAPA, 2000). Atualmente, o MGE encontra-se implantado em mais de $70 \%$ das 40 Unidades de pesquisa da empresa.

De acordo com vários executivos, a implantação do balanced scorecard "não é tão simples quanto parece” (KAPLAN; NORTON, I997:297). Com base nessa afirmação e nas barreiras e problemas identificados por vários autores à implantação do BSC, buscou-se, por meio de um estudo de caso nas Unidades da Embrapa identificar quais fatores interferiram tanto positiva quanto negativamente na implantação do MGE.

A relevância desta pesquisa está no fato de ter sido realizada em uma empresa pública de importância estratégica para o país e por mostrar quais fatores 
interferem no processo de implantação do BSC, instrumento de gestão estratégica em crescente utilização, principalmente por empresas governamentais.

Este texto encontra-se organizado da seguinte maneira: no item I é apresentado o referencial teórico sobre BSC, relacionando-o com o setor público; o item 2 aborda os fatores que interferem na implantação do BSC; no item 3 encontrase a metodologia da pesquisa; no item 4 é apresentada a contextualização do problema, descrevendo-se sobre o planejamento estratégico da Embrapa e sobre o MGE; em seguida, no item 5, apresentam-se os resultados da pesquisa; e, por fim, a conclusão da pesquisa.

\section{BALANCED SCORECARD E SUAS PERSPECTIVAS NAS EMPRESAS PÚBLICAS e PRIVAdAS}

O balanced scorecard é uma ferramenta empresarial que traduz a missão e a estratégia da organização em um conjunto coerente de medidas de desempenho, que propicia a formação de uma estrutura de medição estratégica e de um sistema de gestão eficiente. É uma metodologia que liga as atividades de curto e longo prazo de uma organização com a visão, a missão e a estratégia da empresa, por meio do estabelecimento de metas mensuráveis. Além disso, ele cria uma estrutura, uma linguagem, para comunicar a missão e a estratégia, e utiliza indicadores para informar os funcionários sobre os vetores do sucesso atual e futuro (KAPLAN; NORTON, I997).

Para traduzir a missão e estratégia em objetivos e medidas, o BSC é estruturado em quatro perspectivas diferentes: financeira, do cliente, dos processos internos e do aprendizado e crescimento.

A perspectiva financeira, segundo aqueles autores, sintetiza as conseqüências econômicas imediatas das ações realizadas. Isto é, os indicadores desta perspectiva indicam se a estratégia de uma empresa, sua implementação e execução estão contribuindo para a melhoria dos resultados financeiros. Dessa forma, os objetivos e as medidas das outras três perspectivas têm como foco os objetivos financeiros definidos na perspectiva financeira. Qualquer medida selecionada deve fazer parte de uma cadeia de relações de causa e efeito que culminam com a melhoria do desempenho financeiro.

Nas organizações governamentais e sem fins lucrativos, entretanto, a perspectiva financeira representa uma limitação, não um objetivo. Ela não é o foco das outras perspectivas, uma vez que os indicadores financeiros não demonstram se a organização está cumprindo sua missão. O que indica isso é a satisfação dos clientes (NIVEN, 2003), ou seja, da sociedade. A perspectiva do cliente passa, nesse caso, a ser o foco das outras perspectivas e o sucesso delas passa a 
ser medido pelo grau de eficácia e eficiência com que atendem às necessidades de seus participantes e não pelo desempenho financeiro (KAPLAN; NORTON, I997). Niven (2003) usa o diagrama mostrado na Figura I para diferenciar o uso do BSC em empresas do setor privado daquelas do setor público e sem fins lucrativos.

\section{FIGURA I}

\section{BSC PARA ORGANIZAÇÕES DO SETOR PÚBLICO} E SEM FINS LUCRATIVOS

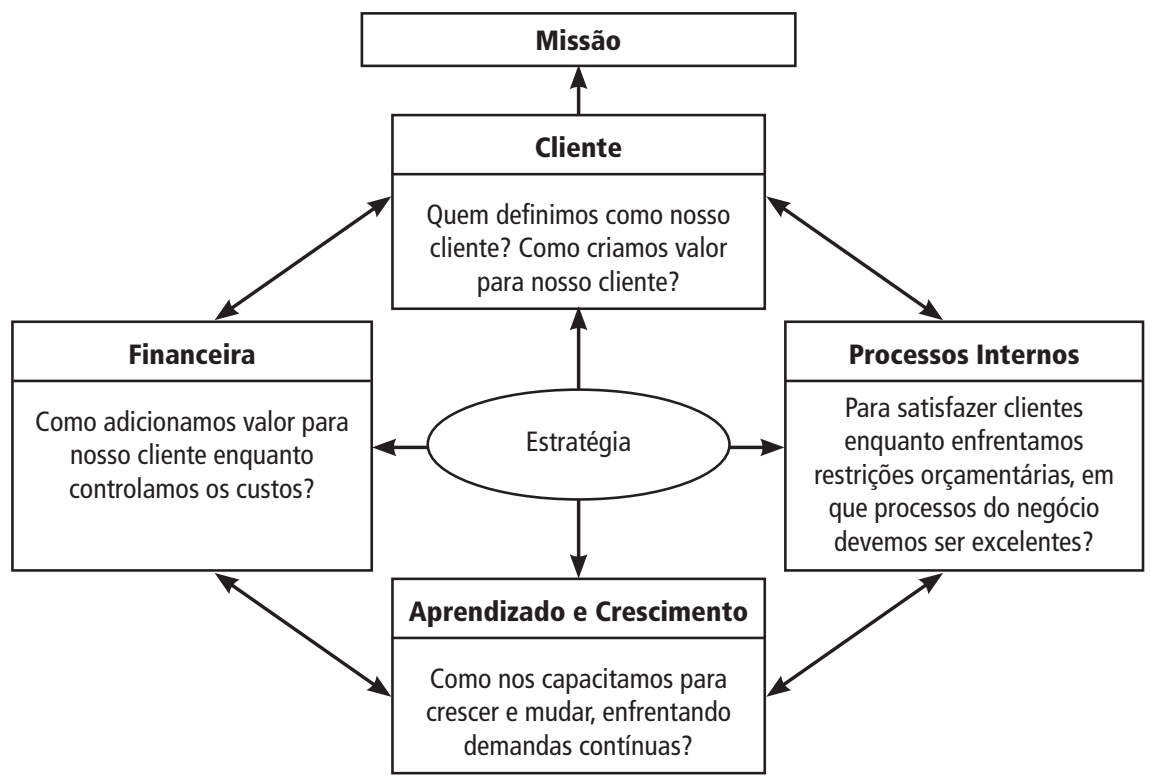

Fonte: (NIVEN, 2003).

A perspectiva do cliente permite a identificação dos segmentos de clientes e mercados nos quais a organização atuará, bem como as medidas de desempenho da organização nesses segmentos-alvo. Nesta perspectiva, normalmente constam medidas essenciais que indicam se uma estratégia foi bem formulada e bem implementada, tais como nível de satisfação do cliente, índice de retenção do cliente, aquisição de novos clientes, lucratividade dos clientes e participação nos segmentos-alvo.

Fazendo uma ligação com a perspectiva financeira, numa relação de causa e efeito, "a perspectiva do cliente permite que os gerentes das unidades de negócios articulem as estratégias de clientes e mercados que proporcionarão maiores lucros financeiros futuros" (KAPLAN; NORTON, I997:27). 
Para instituições do setor privado, a satisfação do cliente e sua fidelidade seriam a causa primária da obtenção de bons resultados financeiros, no entanto para instituições do setor público seria o principal objetivo (RUAS, 2003).

Kaplan e Norton (2000) e Niven (2003) ressaltam a importância da perspectiva do cliente para as instituições governamentais e sem fins lucrativos ao enfatizar a necessidade de inclusão de objetivos abrangentes, ligados à missão da instituição, no alto do scorecard, representando o propósito de longo prazo da organização. "A inserção do objetivo abrangente no balanced scorecard das entidades não lucrativas ou dos órgãos governamentais comunica com nitidez a missão de longo prazo da organização" (KAPLAN; NORTON, 2000:I47). Como exemplo desses objetivos, citam a redução da pobreza e do analfabetismo e a melhoria do meio ambiente.

A perspectiva dos processos internos permite aos executivos a identificação dos processos internos que são críticos para a organização e que, por isso, devese ter excelência. Portanto, as medidas dos processos internos estão voltadas para aqueles que permitem à organização: atrair e reter clientes em segmentos-alvo de mercado; e satisfazer as expectativas dos acionistas em relação a retornos financeiros. Niven (2003) coloca que a chave para o sucesso do BSC está na seleção e medição daqueles processos que permitem, em última instância, atingir a missão da organização.

As abordagens tradicionais de medição de desempenho buscam o monitoramento e a melhoria dos processos existentes. O BSC, além disso, permite a identificação de processos novos, que são críticos para o alcance dos objetivos financeiros e dos clientes, ou seja, para o sucesso da estratégia da empresa.

Tanto para as organizações governamentais e sem fins lucrativos como nas organizações privadas, a perspectiva dos processos internos tem os mesmos objetivos, ou seja, identificar os processos internos que são críticos para a organização e monitorá-los. Nas organizações privadas, porém, o objetivo final é aumentar os ganhos financeiros dos acionistas, enquanto que nas organizações governamentais e sem fins lucrativos é a satisfação dos clientes.

A quarta e última perspectiva do BSC é a do aprendizado e crescimento, que trata da infra-estrutura da empresa, visando o crescimento e melhoria em longo prazo.

Enfatizando a importância da infra-estrutura da empresa em um quadro de intensa competição nos dias de hoje e para o futuro, Kaplan e Norton (I997:29) colocam que "é improvável que as empresas sejam capazes de atingir suas metas de longo prazo para clientes e processos internos utilizando as tecnologias e capacidades atuais".

Os objetivos financeiros, do cliente e dos processos internos só serão atingidos se a empresa tiver uma infra-estrutura que apóie esses objetivos e que 
provenha das pessoas, sistemas e procedimentos organizacionais, entretanto nem sempre as capacidades da infra-estrutura estão adequadas aos objetivos estabelecidos. No BSC essa adequação é feita com os objetivos da perspectiva do aprendizado e crescimento, isto é, com o investimento em capacitação para os empregados, com a melhoria da tecnologia da informação e dos sistemas e com o alinhamento dos procedimentos e rotinas organizacionais (KAPLAN; NORTON, I997).

A gestão das ações estratégicas definidas dentro dessas quatro perspectivas é feita pelo acompanhamento das medidas e indicadores de desempenho. Além disso, essas medidas servem

para articular a estratégia da empresa, para comunicar esta estratégia e para ajudar a alinhar iniciativas individuais, organizacionais e interdepartamentais, com a finalidade de alcançar uma meta comum (KAPLAN; NORTON, I997:25).

Esse processo, segundo os autores, é contínuo e inicia com a definição da missão da organização.

\section{FATORES QUE INTERFEREM NA IMPLANTAÇÃO DO BSC}

Em relação à implantação do BSC, Kaplan e Norton (I997) afirmam que há uma incoerência entre a formulação e a implementação das estratégias, e que isso ocorre devido às barreiras criadas pelos sistemas gerenciais tradicionais, que foram feitos para: criar e comunicar a estratégia; alocar recursos; definir metas e direções; e fornecer feedback. As barreiras identificadas podem ser superadas com a integração do BSC com o novo sistema de gestão estratégica. São elas: visões e estratégias não executadas; estratégias não associadas às metas; estratégias não associadas à alocação de recursos; e feedback tático, não estratégico.

Além das barreiras citadas acima, algumas falhas estruturais e organizacionais dificultam a implantação do BSC. Dentre as falhas estruturais há medidas que mostram a eficiência passada das estratégias da empresa que são úteis para controlar, mas não para comunicar o andamento delas, além de não permitir ajustes. Em relação às falhas organizacionais, aqueles autores citam: delegação do BSC a uma equipe de nível gerencial médio; utilização de indicadores inadequados à empresa; e criação de sistemas de informação para geração de indicadores.

As pessoas que participam do processo de implantação do BSC possuem papéis críticos nesse processo (OLVE, ROY e WETTER, 200I), uma vez que estão colaborando para a implantação de uma mudança radical na filosofia gerencial 
da organização. As seguintes características são desejáveis a essas pessoas: (I) ter total compreensão e estar interiormente motivado pelo novo foco nos objetivos estratégicos de longo prazo; (2) ser capaz de educar a equipe executiva e orientar a tradução da estratégia em objetivos e indicadores específicos de maneira não ameaçadora e de forma a não desencadear reações defensivas; (3) comprometimento e tempo da equipe executiva; (4) acesso fácil ao executivo principal; e (5) facilidade de comunicação (KAPLAN; NORTON, I997).

O Quadro I sintetiza os problemas que inibem o desenvolvimento de organizações focalizadas na estratégia apresentados por Kaplan e Norton (2000 apud SOARES JÚNIOR, 2003).

\section{QUADRO I}

\section{PROBLEMAS DE ORGANIZAÇÕES FOCALIZADAS NA ESTRATÉGIA}

\begin{tabular}{|c|c|}
\hline $\begin{array}{l}\text { Questões } \\
\text { de } \\
\text { transição }\end{array}$ & $\begin{array}{l}\text { Após processos de fusões e aquisições, envolvendo mudanças de controle } \\
\text { e mudanças de liderança, as organizações, por vezes, retrocedem aos siste- } \\
\text { mas gerenciais tradicionais, quando ainda não experimentaram os benefí- } \\
\text { cios da organização focalizada na estratégia. }\end{array}$ \\
\hline $\begin{array}{l}\text { Questões } \\
\text { de projeto }\end{array}$ & $\begin{array}{l}\text { As deficiências no projeto, geralmente, estão associadas à adoção de poucos } \\
\text { ou, em outros casos, de um excesso de indicadores, sem equilíbrio entre os } \\
\text { indicadores de ocorrência e tendência. } \\
\text { Normalmente, são organizações, cujos scorecards não contam a história da } \\
\text { estratégia. São aplicações pontuais e localizadas do conceito, sem o compar- } \\
\text { tilhamento de processos gerenciais de alto nível, tanto na aplicação como } \\
\text { na revisão e feedback. }\end{array}$ \\
\hline $\begin{array}{l}\text { Questões } \\
\text { de } \\
\text { processo }\end{array}$ & $\begin{array}{l}\text { As causas mais comuns de fracasso na implementação do BSC não são } \\
\text { falhas de projeto, mas deficiências nos processos organizacionais: } \\
\text { I. falta de comprometimento da alta administração; } \\
\text { 2. envolvimento de muito poucas pessoas; } \\
\text { 3. encastelamento do scorecard no topo; } \\
\text { 4. processos de desenvolvimento muito longos, o BSC como projeto de } \\
\text { mensuração de ocasião única; } \\
\text { 5. tratamento do BSC como projeto de área de sistemas; } \\
\text { 6. contratação de consultores inexperientes; } \\
\text { 7. implementação do BSC apenas para fins de remuneração (KAPLAN e } \\
\text { NORTON, } 2000, \text { p. } 369 \text { ). }\end{array}$ \\
\hline
\end{tabular}

Fonte: (SOARES JÚNIOR, 2003:2).

Segundo Epstein e Manzoni (I998), a implantação do balanced scorecard é um processo difícil porque significa introduzir uma mudança na organização e mudanças afetam a disponibilidade de informações relacionadas com o desempenho organizacional, o que pode representar uma ameaça ao processo, princi- 
palmente se houver mudança no equilíbrio do poder na organização. Os autores afirmam que sistemas de medição mal projetados e a dificuldade de implantá-los são as duas principais razões de falhas na implementação do balanced scorecard.

Schneiderman (I999) reforça a tese de que o balanced scorecard implica mudança organizacional e acrescenta que as organizações somente mudam quando empregados compartilham a propriedade das metas e dos meios. Para esse autor, as razões para a maioria das falhas na implementação do balanced scorecard são:

I) as variáveis independentes (não financeiras) são identificadas incorretamente como direcionadores primários da satisfação futura dos stakeholders. Isso ocorre porque os requerimentos de stakeholders não proprietários, tais como empregados, clientes, fornecedores, comunidades e até futuras gerações dificultam a identificação das medidas que têm maior peso para a organização, que são as medidas financeiras;

2) as medidas são mal definidas. A falta de experiência em definir medidas não financeiras contribui para isso. O autor classifica as medidas como de resultados mais úteis aos gerentes, e de processos, mais utilizadas pela equipe de melhoria por permitir identificar os pontos onde as melhorias terão maior impacto. Ainda segundo o autor, as boas medidas são aquelas que: (a) são uma procuração confiável para a satisfação dos stakeholders; (b) são orientadas para fraquezas ou defeitos (ideal que tenha valor zero) e avaliação contínua; (c) são simples e fácil de entender; (d) têm definição operacional bem documentada, precisa, consistente, apropriadamente regulada e metrologicamente sólida; (e) são oportunas e acessíveis para aqueles que podem melhor usá-las; (f) são ligadas ao sistema de dados, o que facilita a identificação das causas centrais das lacunas nos resultados do scorecard; e (g) têm um processo formal para revisão e refinamento contínuos;

3) as metas são negociadas ao invés de basearem-se nos desejos dos stakeholders, nos limites fundamentais do processo e na melhoria das capacidades dos processos. É necessário ter metas baseadas no conhecimento dos meios que serão utilizados para atingi-las, visando a não criação de metas inferiores ou superiores à capacidade da organização;

4) não há sistema organizado que quebre as metas de alto nível em subprocessos de níveis inferiores onde melhorias reais das atividades ocorrem, dificultando o alinhamento das metas intermediárias e das atividades dos empregados com as metas de alto nível;

5) não uso do estado da arte em melhoria de processo. Isso tem levado muitas empresas fazerem melhoria de processo por meio de tentativas e erros ao invés de usar os métodos científicos existentes; e 
6) falta de ligação entre o lado financeiro e o não financeiro no scorecard. A ligação das variáveis dependentes (financeiras) com as independentes (não financeiras) numa relação de causa e efeito garante que o sucesso dos indicadores não financeiros represente o sucesso do negócio.

Para Roest (1997), alguns pontos fundamentais, chamados de "regras de ouro", devem ser observados na implementação do balanced scorecard: (I) não existe uma solução padrão: todas as empresas são diferentes; (2) o apoio da alta administração é essencial; (3) a estratégia é o ponto de partida; (4) os objetivos e medidas devem ser limitados e equilibrados, porém, relevantes; (5) o intervalo de tempo entre análise e implementação não pode ser muito longo nem muito curto; (6) adotar abordagens top-down e bottom up; (7) o balanced scorecard sugere forte ligação entre sistemas de informação e medição do desempenho; (8) considerar os sistemas de comunicação como ponto de partida; (9) considerar o efeito dos indicadores de desempenho no comportamento; e (Iо) nem todas as medidas podem ser quantificadas.

Guilherme e Goldszmidt (2003), a partir de uma revisão de literatura, identificaram quatorze fatores críticos para a implantação do balanced scorecard, os quais foram divididos em dois grupos: fatores organizacionais e fatores relacionados ao processo de implantação e uso do BSC. Os fatores críticos do primeiro grupo relacionaram-se a processos organizacionais, cultura organizacional, estratégia e sistemas de informação. O segundo grupo apresentou fatores como: consciência da real finalidade do projeto e do esforço necessário; liderança e apoio da alta administração; equipe de projeto; individualização do projeto; abrangência do projeto e projeto piloto; elaboração dos indicadores; simplicidade; comunicação e disseminação; dinâmica da aplicação do BSC e integração com os processos gerenciais.

Para o sucesso na implantação do balanced scorecard, Olve, Roy e Wetter (200I) ressaltam a importância da alta direção estar totalmente comprometida com o processo. Não basta demonstrar esse comprometimento, é necessário participar ativamente no desenvolvimento do BSC, principalmente no início do processo, assegurar que a tarefa terá alta prioridade e que será totalmente apoiada por toda a organização. Os autores acrescentam, ainda, que a definição das pessoas que participarão do processo e o momento dessa participação são também fundamentais para o êxito na implantação do BSC, ressaltando a importância dessas pessoas estarem motivadas e comprometidas.

Bieker (2003) reforça a colocação de Olve, Roy e Wetter (200I) ao enfatizar que o comprometimento da alta administração é uma importante pré-condição para a aceitação interna do balanced scorecard, assim como contar com empregados comprometidos e proativos. Acrescenta que, como o BSC poderia substituir os sistemas de administração existentes, os gerentes poderiam ter medo de per- 
der poder, além de sentir uma pressão por melhor desempenho, o que poderia gerar uma desaprovação do balanced scorecard na organização.

\section{4 metodologia da pesquisa}

O presente estudo caracteriza-se como uma pesquisa exploratória e descritiva. Exploratória porque visa a levantar questões e hipóteses para futuros estudos e descritiva porque pretende descrever os fatos e fenômenos de determinada realidade.

Segundo Gil (I994) a pesquisa exploratória tem como objetivo proporcionar maior familiaridade com o problema, com vistas a torná-lo mais explícito ou a construir hipóteses para estudos futuros. Pode-se dizer que essas pesquisas têm como principal objetivo o aprimoramento de idéias ou a descoberta de intuições. Ainda segundo o mesmo autor, a pesquisa descritiva busca, primordialmente, descrever as características de determinado fenômeno e estabelecer possíveis relações entre variáveis.

A pesquisa de campo caracterizou-se por um estudo de caso único na Empresa Brasileira de Pesquisa Agropecuária (Embrapa). De acordo com Yin (200I), o estudo de caso é um modo de pesquisa empírica que investiga fenômenos contemporâneos em seu contexto real, quando os limites entre fenômeno e o contexto não estão claramente definidos.

Um caso, segundo Yin (200I), corresponde a uma unidade de análise, que pode ser um evento, uma entidade, um indivíduo, uma decisão, um programa, um processo de implantação de alguma coisa em uma organização ou uma mudança organizacional. Assim, a unidade de análise desta pesquisa corresponde ao processo de implantação do MGE na Embrapa.

De acordo com a classificação apresentada por Yin (200I), um estudo de caso, além de único ou múltiplo, pode ser holístico ou incorporado. A combinação desses tipos de estudo de caso gera quatro tipos de projetos: estudo de caso único holístico (tipo I); estudo de caso único incorporado (tipo 2); estudo de caso múltiplo holístico (tipo 3); e estudo de caso múltiplo incorporado (tipo 4).

Em um estudo de caso, pode-se dar atenção a uma subunidade de análise ou a várias; essa distinção na quantidade de subunidades é que define se um estudo de caso é holístico ou incorporado. É holístico quando se tem apenas uma subunidade de análise e incorporado quando se tem mais de uma. Segundo Yin (200I), uma subunidade de análise pode ser um indivíduo, uma reunião, uma função ou um local determinado. Desse modo, este estudo de caso caracteriza-se como um estudo de caso único e incorporado (Tipo 2), pois foi envolvida mais de uma subunidade de análise: os responsáveis pelo BSC das Unidades da Embrapa e o responsável pelo MGE. 
Para o julgamento de uma pesquisa social empírica, quatro critérios vêm sendo utilizados: validade do constructo; validade interna; validade externa; e confiabilidade (YIN, 200I). Para aumentar a validade do constructo várias fontes de evidências foram utilizadas (responsáveis pelo BSC, responsável pelo MGE e documentos e publicações da empresa, apresentados no referencial teórico). Acerca da validade interna, Yin (200I:57) coloca que esta "é uma preocupação apenas para estudos de caso causais (ou explanatórios)", não sendo aplicável a estudos descritivos ou exploratórios, como o deste estudo.

O terceiro critério - validade externa - trata da generalização da pesquisa. Para Yin (200I), o estudo de caso não permite generalização estatística, como um levantamento, mas permite a generalização analítica, ou seja, permite a generalização de um conjunto particular de resultados a alguma teoria mais ampla, por meio da replicação das descobertas em outros locais. Como este estudo foi o primeiro a ser realizado, a validade externa ainda não foi realizada, contudo permitiu a comparação com a teoria existente e construção de hipóteses para estudos futuros.

Yin (200I) coloca que a criação elaboração de um protocolo de estudo de caso e a criação de um banco de dados contribui para o alcance do critério de confiabilidade. Seguindo essa orientação, seguiu-se um protocolo de estudo de caso contendo a visão geral do projeto de estudo de caso, os procedimentos de campo, questões do estudo de caso e um guia para o relatório de estudo de caso. Além disso, um banco de dados do estudo de caso, contendo os questionários e os documentos, foi elaborado.

A população da pesquisa foi formada por 3I das 40 Unidades Descentralizadas da empresa, uma vez que nove não estavam presentes na relação disponibilizada na Intranet da Embrapa Sede. Como estratégia de entrada em campo, utilizou-se a Internet para o envio dos questionários via e-mail.

Como instrumento de coleta dos dados, foi utilizado um questionário semiestruturado, contendo perguntas dicotômicas, tricotômicas, de múltipla escolha, escalar e numéricas, totalizando 25 perguntas. Com estas perguntas buscou-se coletar informações sobre quatro categorias empíricas: (I) situação do MGE na Unidade; (2) perfil do gerente do modelo; (3) participação da chefia da Unidade no MGE; e (4) perfil dos gerentes de objetivos estratégicos.

O Questionário continha ainda três perguntas abertas para identificar os fatores que influenciaram positiva e negativamente a implantação do MGE na Unidade e para o entrevistado acrescentar algum comentário que considerasse importante sobre a implantação do MGE. Os fatores positivos e negativos foram informados segundo o grau de importância. $\mathrm{Na}$ análise desses fatores, esse grau de importância se transformou em peso para obtenção do total ponderado do fator. 
O trabalho de campo foi realizado no período de julho a agosto de 2003 e iniciou com o envio dos questionários a 3I gerentes do MGE das Unidades da Embrapa. O gerente do MGE foi escolhido para responder o questionário em função de ser a pessoa que trabalha diretamente com o modelo e com os gerentes de objetivos, além de ser o responsável pela implantação. Apenas dez Unidades responderam, correspondendo a uma amostra de $32,26 \%$ da população. Foi enviado, via e-mail, um outro questionário, formado apenas pelas questões abertas, ao coordenador de todo processo de implantação do MGE, cujo objetivo era confrontar o resultado da pesquisa com a visão de quem participou da implantação em toda a empresa.

$\mathrm{Na}$ fase da análise, foram feitas a tabulação e análise dos dados obtidos nos questionários. Utilizou-se dos recursos da planilha eletrônica Excel para classificação, categorização e ponderação dos fatores que influenciaram na implantação do MGE. Os pesos utilizados para a ponderação desses fatores variaram de I (menos importante) a 5 (mais importante).

\section{Planejamento e gestão ESTRATÉGICA DA EMBRAPA}

A Embrapa é uma empresa pública que tem como missão "viabilizar soluções para o desenvolvimento sustentável do agronegócio brasileiro por meio de geração, adaptação e transferência de conhecimentos e tecnologias em benefício da sociedade" (EMBRAPA, 2002:I) e está presente em quase todo o Brasil por meio de suas Unidades de Pesquisa.

No seu processo de planejamento estratégico, a Embrapa desenvolveu várias ações para aprimorar a formulação e execução das estratégias, tais como a elaboração do documento "Planejamento estratégico: conceitos e metodologia para sua formulação" e a internalização em sua cultura dos princípios do planejamento estratégico como instrumento de tomada de decisões (GOLLO; CASTRO, 200I). Apesar disso,

o processo de Planejamento Estratégico, mesmo estabelecendo uma direção, tem se mostrado deficiente na implantação das ações estratégicas, isto é, daquelas ações que efetivamente conduzem a Empresa ao estado futuro desejado (FRESNEDA, 2002:4).

Visando a buscar uma solução que melhorasse a implantação dos planos estratégicos, a empresa iniciou, em I997, um projeto piloto em uma de suas Unidades de Pesquisa com o intuito de testar e adaptar o balanced scorecard. O resultado desse projeto foi o Modelo de Gestão Estratégica (MGE), objeto de estudo desse trabalho. 
O MGE possui em sua estrutura quatro perspectivas, seguindo o padrão do BSC: institucional e financeira; clientes; processos internos; e aprendizado e crescimento, esta última com ênfase em recursos humanos e informação. Foi criada a perspectiva institucional e somada à perspectiva financeira, em função de a empresa ser uma instituição pública, sem fins lucrativos e com objetivos sociais.

Além das perspectivas, o MGE possui quatro temas estratégicos que servem de transição entre a visão e os objetivos estratégicos. Eles compõem a parte essencial da visão da Embrapa, são eles: orientação para o mercado; inovação e qualidade em Pesquisa e Desenvolvimento (P\&D); excelência em gestão institucional; e reconhecimento institucional.

A distribuição dos objetivos estratégicos nas perspectivas e nos temas estratégicos forma o mapa estratégico da Embrapa (Figura 2). Neste mapa, a linha que liga os objetivos representa a relação de dependência entre eles (causa-efeito); os temas estratégicos e os objetivos estratégicos de números I, 6, 7, 8 e 9, que estão diferenciados no diagrama, são responsáveis pela integração entre o MGE Corporativo e o MGE das Unidades, ou seja, pelo alinhamento estratégico da empresa.

Para cada objetivo estratégico do MGE existe um Plano de Ação Estratégico (PAE), onde são especificadas as ações a serem realizadas e as informações necessárias ao seu acompanhamento e avaliação, tais como responsável, objetivos estratégicos relacionados, prioridade de execução, prazo, estratégias de implantação e resultados esperados.

\section{FIGURA 2}

\section{DIAGRAMA DO MODELO DE GESTÃO ESTRATÉGICA}

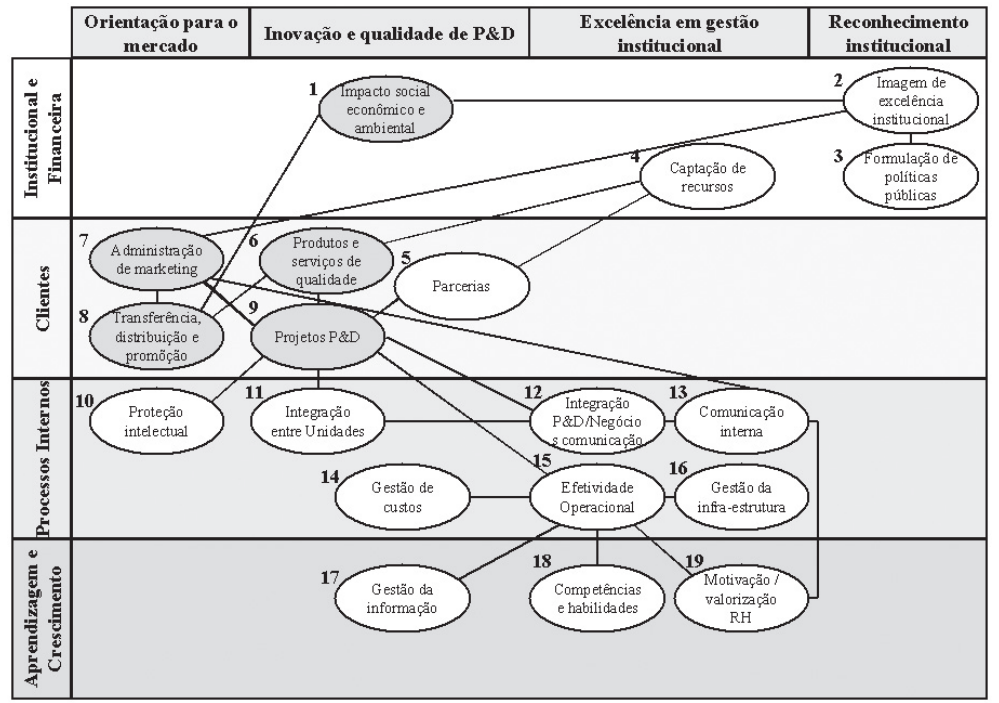

Fonte: (EMBRAPA, 2000). 


\section{Resultados da pesquisa}

A análise dos dados obtidos com os questionários será dividida em três partes: (I) análise descritiva das questões fechadas, as quais permitem identificar a situação do MGE nas Unidades; (2) análise dos fatores que interferiram na implantação do modelo; e (3) análise destes fatores em relação às questões fechadas.

\subsection{SITUAÇÃO DO MGE NAS UNIDADES}

Para a identificação da fase em que se encontra a implantação do MGE, foram apresentadas cinco opções: (I) não-implantado; (2) implantado, mas sem execução do PAE; (3) implantado e com o PAE em execução; (4) implantado e com indicadores de desempenho analisados; e (5) todas as fases anteriores já cumpridas e executando novo PAE. O Gráfico I mostra que cinco das dez Unidades pesquisadas (50\%) estão com o MGE implantado, entretanto o PAE não está sendo executado. Mostra também que apenas uma já analisou os indicadores de desempenho. Esta variável permite visualizar o estágio de evolução do processo de implantação do MGE nas Unidades da empresa e serve, também, como parâmetro para análise das outras variáveis, bem como dos fatores que interferiram no processo. A partir desses dados, pode-se perceber que a empresa encontrou dificuldades para a implantação de um modelo de gestão baseado no balanced scorecard.

\section{GRÁFICO I}

\section{FASES DE IMPLANTAÇÃO DO MGE}
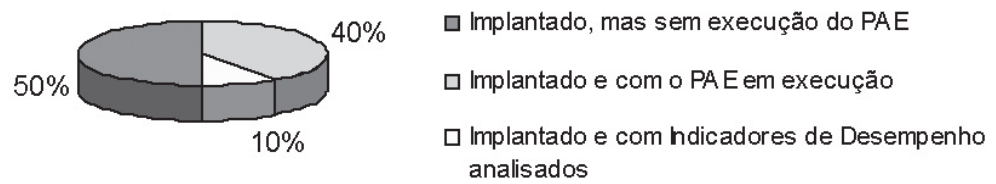
analisados

Fonte: Pesquisa de campo.

Em relação ao tempo de implantação do MGE, as primeiras Unidades iniciaram a implantação em I999 e as últimas em 200I. Analisando o tempo de implantação e a fase em que o MGE se encontra (Gráfico 2), observa-se que das sete Unidades que têm mais tempo de implantação (B, C, D, E, F, G, J), apenas duas (C, F) estão com o Plano de Ação Estratégica (PAE) em execução, ou seja, as Unidades que têm mais tempo de implantação estão nas fases iniciais do processo. Esses dados permitem inferir que nessas Unidades os fatores negativos que influenciaram a implantação foram mais fortes que os positivos e que, ao longo do tempo, enfraqueceram, permitindo que o processo avançasse mais nas Unidades que iniciaram a implantação depois, ou seja, as barreiras foram sendo removidas. 
GRÁFICO 2

FASE DE IMPLANTAÇÃO DO MGE EM RELAÇÃO AO TEMPO

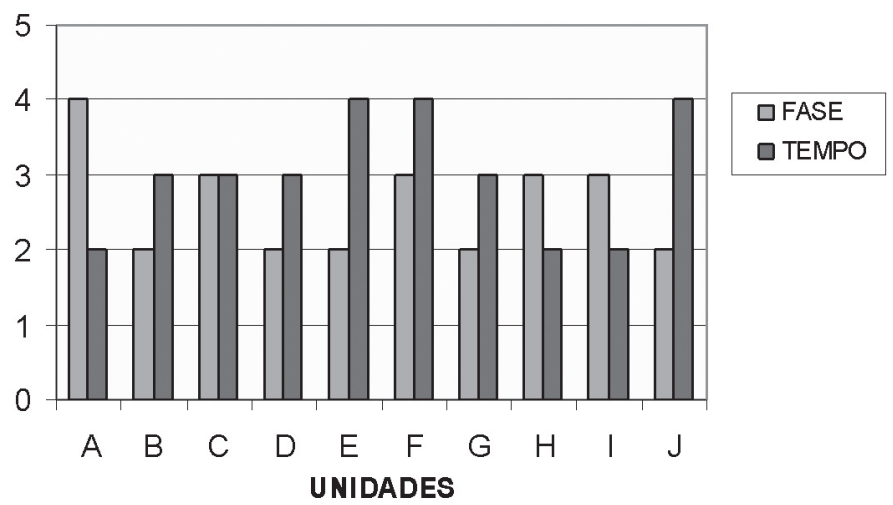

Fonte: Pesquisa de campo.

A análise dos dados relativos aos dez gerentes do MGE que responderam os questionários mostrou que todos já leram sobre o BSC, oito já participaram de treinamento em gestão (80\%), mas que apenas seis participaram de treinamento sobre o MGE (60\%). Dos quatro que não receberam treinamento, apenas um está desde o início da implantação do MGE, o que mostra que houve uma preocupação com treinamento dos gerentes no início da implantação do modelo (EMBRAPA, I999).

Em relação aos gerentes de objetivos estratégicos, entretanto apenas três Unidades informaram que todos haviam sido treinados. A participação ou não dos gerentes de objetivos estratégicos em treinamentos não demonstrou ter interferido no andamento da implantação do modelo.

O alinhamento do Plano de Ação Estratégica (PAE) com o Plano Diretor da Unidade (PDU) foi analisado utilizando-se a escala de Likert, que variou de "nenhum" (I) a "totalmente" (5). O alinhamento entre o PAE e PDU obteve 3,6 como média, índice próximo ao obtido em relação ao conhecimento que os gerentes de objetivos estratégicos têm do PDU da Unidade, que foi de 3,9. Esses dados indicam que mesmo que todas as ações previstas no PAE fossem executadas, os objetivos estratégicos da empresa não seriam totalmente atingidas, uma vez que nem todas as ações estão alinhadas com o planejamento estratégico. Este problema remonta às questões de projeto apresentadas por Kaplan e Norton (2000), isto é, os scorecards não contêm a história da estratégia.

Os dados relativos à freqüência com que as reuniões de acompanhamento do MGE são realizadas mostraram que cada Unidade adota a freqüência que acha adequada. Há variação de quinzenal a semestral. Duas Unidades informaram não haver freqüência definida. Analisando a freqüência com a fase, observa- 
se que as Unidades que ainda estão nas fases iniciais da implantação do MGE possuem baixa freqüência de reunião de acompanhamento, prejudicando o feedback sobre o andamento do processo. O feedback foi outro ponto enfatizado pelos autores do BSC como importante para o sucesso do modelo.

A quantidade de objetivos estratégicos de cada Unidade varia de 6 a I3. Em oito das dez Unidades, esses objetivos foram implantados na mesma época. Apenas duas Unidades implantaram um objetivo estratégico por vez, entretanto a forma de implantação não interferiu na fase em que se encontra o MGE.

No documento que descreve o MGE (EMBRAPA, 2002) há uma referência ao perfil desejado do gerente de objetivo estratégico, o qual não é observado em quatro das dez Unidades pesquisadas. No entanto, os dados não demonstraram relação com o estágio de implantação do modelo.

Com relação à alta direção da Unidade, buscou-se verificar sua participação, bem como a importância que ela dá ao MGE. Identificou-se que todas têm pelo menos um dos altos gestores da Unidade participando como gerente do modelo ou de objetivo estratégico, e que nas cinco Unidades que mais avançaram na implantação do MGE (A, C, F, H, I), o envolvimento/apoio da chefia foi apresentado como muito bom em três (A, F, H) e regular em duas (C, I).

Outra questão relacionada à alta direção da Unidade e que apresentou muita variação, foi se ela considera o MGE importante para atingir a visão e missão da Unidade. O coeficiente de correlação desta questão com o grau de envolvimento foi de 0,960943 (significante a I\%), demonstrando que o envolvimento/apoio possui uma correlação positiva e muito forte com o fato de a alta direção considerar o MGE importante para a Unidade atingir sua missão e visão. O Gráfico 3 mostra os dados dessas questões.

\section{GRÁFICO 3}

FASE DE DESENVOLVIMENTO DO MGE E ENVOLVIMENTO DA ALTA DIREÇÃO

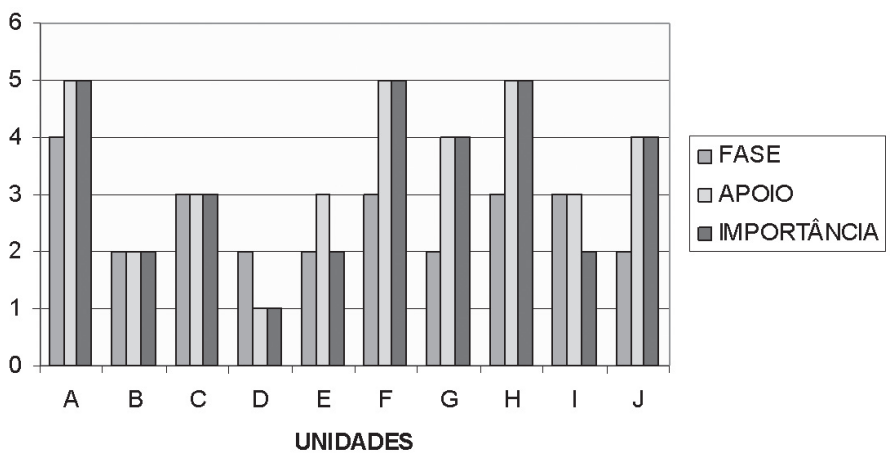

Fonte: Pesquisa de campo. 


\subsection{FATORES QUE INTERFEREM NA IMPLANTAÇÃO DO MGE}

Para a identificação dos fatores que influenciaram a implantação do MGE nas Unidades, foram feitas duas perguntas: a primeira solicitou que o gerente do modelo citasse cinco fatores, em ordem decrescente de importância, que mais contribuíram positivamente na implantação do MGE; a segunda seguiu a mesma metodologia, mas relacionada aos fatores que interferiram negativamente.

Adotaram-se os mesmos procedimentos metodológicos para os dois tipos de fatores: digitação dos dados na planilha eletrônica Excel; agrupamento dos fatores por categoria; e ordenação decrescente de importância.

O Quadro 2 sintetiza as categorias que interferiram positivamente na implantação do MGE e apresenta as quantidades citadas de cada categoria. Ressalta-se que o grau 5 é o mais importante e que algumas unidades não citaram todos os cinco fatores. Ao todo seis fatores não foram preenchidos.

A análise da última coluna (Total Ponderado), que mostra a soma do produto das freqüências de respostas pelos respectivos graus de importância, permite afirmar que a equipe responsável pela implantação do MGE foi o fator que mais contribuiu positivamente no processo, seguidos pelas próprias características do modelo e pelo envolvimento/apoio da chefia da Unidade. Dos três principais fatores, dois estão relacionados com pessoas, ou seja, a equipe envolvida com o modelo de gestão tem papel crítico nesse processo (BIEKER, 2003; GUILHERME; GOLDSZMIDT, 2003; KAPLAN; NORTON, I997; OLVE, ROY e WETTER, 200I).

QUADRO 2

CATEGORIAS QUE INTERFERIRAM POSITIVAMENTE NA IMPLANTAÇÃO DO MGE

\begin{tabular}{|c|c|c|c|c|c|c|c|}
\hline \multirow[t]{2}{*}{ Categorias Positivas } & \multicolumn{5}{|c|}{ Grau de Importância } & \multirow{2}{*}{$\begin{array}{l}\text { Freq. } \\
\text { Total } \\
\end{array}$} & \multirow{2}{*}{$\begin{array}{l}\text { Total } \\
\text { Pond. }\end{array}$} \\
\hline & 5 & 4 & 3 & 2 & $\mathrm{I}$ & & \\
\hline Equipe responsável pela implantação na Unidade & 2 & 7 & 3 & $\mathrm{I}$ & 2 & $\mathrm{I} 5$ & $5 \mathrm{I}$ \\
\hline O MGE como instrumento de gestão & $\mathrm{I}$ & I & 3 & 2 & I & 8 & 23 \\
\hline Envolvimento/apoio da chefia da Unidade & 2 & $\mathrm{I}$ & - & 3 & I & 7 & $2 \mathrm{I}$ \\
\hline Envolvimento/apoio da direção da Embrapa Sede & 3 & - & - & - & - & 3 & I5 \\
\hline $\begin{array}{l}\text { Envolvimento/apoio do Departamento de } \\
\text { Organização e Desenvolvimento (DOD) }\end{array}$ & - & I & 2 & - & I & 4 & II \\
\hline Estrutura administrativa & $\mathrm{I}$ & - & $\mathrm{I}$ & - & - & 2 & 8 \\
\hline PDU definido adequadamente & $\mathrm{I}$ & - & - & - & - & $\mathrm{I}$ & 5 \\
\hline Outros & - & - & - & $\mathrm{I}$ & 2 & 3 & 4 \\
\hline Inclusão das atividades no SAAD & - & - & $\mathrm{I}$ & - & - & $\mathrm{I}$ & 3 \\
\hline
\end{tabular}

Fonte: Pesquisa de campo. 
A análise dos fatores que interferiram negativamente na implantação do MGE seguiu a mesma metodologia dos fatores que contribuíram positivamente. O Quadro 3 mostra o resultado dessa análise. Foram citados 46 fatores negativos.

\section{QUADRO 3}

CATEGORIAS QUE INTERFERIRAM NEGATIVAMENTE NA IMPLANTAÇÃO DO MGE

\begin{tabular}{|c|c|c|c|c|c|c|c|}
\hline \multirow[t]{2}{*}{ Categorias Negativas } & \multicolumn{5}{|c|}{ Grau de Importância } & \multirow{2}{*}{$\begin{array}{l}\text { Freq. } \\
\text { Total } \\
\end{array}$} & \multirow{2}{*}{$\begin{array}{l}\text { Total } \\
\text { Pond. }\end{array}$} \\
\hline & 5 & 4 & 3 & 2 & $\mathrm{I}$ & & \\
\hline Equipe responsável pela implantação na Unidade & 3 & 2 & 4 & 2 & 3 & I4 & 42 \\
\hline Envolvimento/apoio da chefia da Unidade & 2 & I & - & I & - & 4 & I6 \\
\hline Elaboração do projeto (estratégias/indicadores) & - & 2 & $\mathrm{I}$ & 2 & $\mathrm{I}$ & 6 & I6 \\
\hline Cultura da empresa & I & $\mathrm{I}$ & 2 & - & $\mathrm{I}$ & 5 & I6 \\
\hline O MGE como instrumento de gestão & $\mathrm{I}$ & I & $\mathrm{I}$ & I & $\mathrm{I}$ & 5 & I5 \\
\hline Sistema informatizado/integração & $\mathrm{I}$ & I & $\mathrm{I}$ & - & - & 3 & $\mathrm{I} 2$ \\
\hline Estrutura administrativa & I & - & - & I & - & 2 & 7 \\
\hline Envolvimento/apoio da direção da Embrapa Sede & - & I & - & - & $\mathrm{I}$ & 2 & 5 \\
\hline Processo de comunicação & - & I & - & - & $\mathrm{I}$ & 2 & 5 \\
\hline Recursos financeiros & - & - & $\mathrm{I}$ & I & - & 2 & 5 \\
\hline Sindicato & I & - & - & - & - & I & 5 \\
\hline
\end{tabular}

Fonte: Pesquisa de campo.

Analisando o total ponderado do Quadro 3 deduz-se que "Equipe responsável pela implantação na Unidade" foi o fator que mais interferiu negativamente no processo, seguido por três fatores com a mesma pontuação: o envolvimento/ apoio da chefia da Unidade, elaboração do projeto e a cultura da empresa.

Esses fatores mostram que algumas barreiras à implantação do balanced scorecard citadas pelos autores referenciados, foram encontradas na pesquisa, são elas: perfil inadequado e falta de comprometimento da equipe de implantação do modelo (BIEKER, 2003; GUILHERME; GOLDSZMIDT, 2003; KAPLAN; NORTON, I997; OLVE, ROY e WETTER, 200I); falta de apoio e envolvimento da alta administração (BIEKER, 2003; GUILHERME; GOLDSZMIDT, 2003; KAPLAN; NORTON, 2000; OLVE, ROY e WETTER, 200I; ROEST, I997); a cultura da empresa dificultando as mudanças organizacionais (EPSTEIN; MANZONI, I998; GUILHERME; GOLDSZMIDT, 2003); e, como conseqüência desses três, questões relacionadas às estratégias e aos indicadores, agrupados na categoria "Elaboração do projeto" (EPSTEIN; MANZONI, I998; GUILHERME; GOLDSZMIDT, 2003; KAPLAN; NORTON, I997, 2000; ROEST, I997; SCHNEIDERMAN, I999). 


\subsection{FATORES VERSUS QUESTÕES FECHADAS}

Nesta seção será feito o relacionamento dos fatores citados nas questões abertas com os dados das questões fechadas para a Unidade que mais avançou na implantação do MGE, bem como para aquelas que estão nos estágios iniciais do processo.

A Unidade que está mais à frente no processo citou a adequada definição do PDU, o envolvimento da chefia no processo e a criação de um modelo enxuto como os principais fatores que contribuíram positivamente para o andamento do processo. Nesta Unidade foram definidos oito objetivos estratégicos (a média é ı); o alinhamento do MGE com o PDU está no nível 4 de uma escala de i a 5; as reuniões de acompanhamento do modelo ocorrem mensalmente; o gerente do modelo está desde o início e participou de treinamentos em gestão e sobre o MGE, além de ter leituras sobre o balanced scorecard; o empenho/apoio da chefia bem como o grau de importância que foi dado ao MGE foi máximo; o perfil do gerente de objetivo estratégico é observado quando da sua seleção e todos receberam treinamento sobre o MGE.

Para a análise das unidades que ainda estão na fase inicial da implantação, consideraram-se aquelas que informaram ter implantado o MGE, mas que ainda não estão executando o Plano de Ação Estratégico. Cinco das dez unidades pesquisadas estão nesta fase. Os principais fatores que dificultaram a implantação do MGE para essas unidades estão relacionados: ao envolvimento/apoio da chefia; à estrutura hierárquica; às ações do sindicato; ao sistema informatizado; e aos gerentes. De modo geral, estas Unidades possuem as seguintes características: nível médio de alinhamento entre MGE e PDU; baixa freqüência de reunião; alta rotatividade dos gerentes do modelo (em apenas uma delas o gerente do modelo está desde o início); pouco empenho/apoio das chefias (média $=2,8$ ), próximo ao grau de importância dado ao MGE que foi de 2,6; o perfil do gerente de objetivo estratégico não é sempre observado no momento da seleção, além de não terem recebido treinamento sobre o MGE.

Percebeu-se a ausência de informação em relação a indicadores de desempenho, o que pode ser explicado pelo fato de apenas uma unidade ter chegado ao estágio de análise de indicadores. Em função disso, fatores relacionados às questões de projeto como excesso ou falta de indicadores e dificuldade de implementação de mecanismos de coleta de dados para os indicadores não foram citados.

Para verificar se os fatores identificados na pesquisa coincidiam com a opinião do responsável pela implantação do modelo de gestão na Embrapa, aplicou-se um questionário, via e-mail, a este responsável. Segundo ele, o apoio do diretor-presidente ao projeto e o fato de ter sido o primeiro projeto de mudança organizacional na empresa, construído e implantado de forma democrática e 
participativa, foram os fatores positivos. Os fatores que dificultaram a implantação citados foram: o não envolvimento de parte das chefias de unidades centrais e descentralizadas por receio de perder o poder, conforme citado por Epstein e Manzoni (I998); falta de pensamento e ação estratégica por parte desses gerentes; demora de uma solução automatizada de suporte ao MGE; e desinteresse na integração do MGE com outros instrumentos de gestão existentes.

\section{CONCLUSÕES}

Os estudos mostraram que metade das unidades pesquisadas formulou o Modelo de Gestão Estratégica, mas não o implantaram, uma vez que ainda não iniciaram a execução do Plano de Ação Estratégica. Retorna-se, portanto, à questão da formulação versus implantação citada no início deste texto, entretanto o tempo não pode ser citado como justificativa à não implantação, uma vez que as unidades que iniciaram o processo depois estão em estágios mais avançados, o que permite concluir que fatores interferiram na implantação do MGE.

Pôde-se perceber que existem muitas barreiras à implantação de uma metodologia de gestão baseada no balanced scorecard, principalmente se não existir na empresa uma cultura de gestão estratégica no quadro gerencial, pois os fatores que mais interferiram, tanto positiva como negativamente, na implantação do Modelo de Gestão Estratégica na Embrapa estão relacionados ao quadro gerencial em todos os níveis, seja na alta direção da empresa, na chefia da unidade, no gerente do modelo ou nos gerentes de objetivos estratégicos.

A análise das categorias positivas e negativas permitiu identificar que foram citados vários fatores relacionados aos gerentes. De um total de 44 fatores positivos, 29 (65,91\%) estão diretamente relacionados ao quadro gerencial. Em relação aos fatores negativos, 20 fatores $(43,48 \%)$ dos 46 citados também se relacionam aos gerentes. Como as pessoas envolvidas na implantação do BSC possuem papéis críticos para o sucesso do processo, vê-se como fundamental a análise do perfil das pessoas envolvidas, que pode ser feita, por exemplo, a partir das características desejáveis apresentadas por Kaplan e Norton (I997).

Dentre os fatores citados, o envolvimento/apoio da chefia da unidade surgiu como um dos principais fatores positivos da unidade que mais avançou na implantação do MGE e como um dos principais fatores negativos das unidades que menos avançaram. Isso indica ser este um fator decisivo para o sucesso na implantação de um instrumento de gestão como o balanced scorecard.

Este fator pode ser visto, ainda, como a causa de vários outros, tanto positivos como negativos, tais como o nível de alinhamento entre MGE e PDU, criação de um modelo enxuto, freqüência de reuniões e perfil dos envolvidos. Estes fatores poderão ser positivos ou negativos em função do nível de envolvimento/apoio da chefia dado ao processo. 
Acerca dos fatores que inibem o desenvolvimento de organizações focalizadas na estratégia, foram identificados alguns relacionados às questões de projeto e outros às questões de processo, mas nenhum relacionado às questões de transição. Contudo, observou-se que a alta direção da empresa está preocupada com as questões de transição.

Periodicamente, por meio de seleção pública, há mudança nos gestores das unidades da empresa, o que pode interferir na utilização dos instrumentos de gestão e, por conseqüência, na condução das ações estratégicas. Ciente desse problema, a alta direção da empresa está revisando a "norma para seleção de chefes, de forma a introduzir no processo habilitatório público essa questão relevante dos novos tempos, que é a capacidade gerencial dos candidatos" (EMBRAPA, 2003:I) e investindo na melhoria da capacidade gerencial dos dirigentes.

Essa modificação nas normas de seleção de chefes pode provocar mudanças na situação do MGE das Unidades, uma vez que, em tese, os gestores teriam melhor capacidade gerencial. Nesse contexto, surge uma questão para pesquisas futuras: o MGE das unidades cujos gestores foram selecionados por esse novo processo de seleção terão o fortalecimento dos fatores gerenciais positivos e o enfraquecimento dos fatores gerenciais negativos? A hipótese subjacente a esta questão é que sim.

Este estudo, embora limitado pelo número de Unidades estudadas, mostrou que o sucesso da implantação do BSC depende principalmente das pessoas envolvidas, concordando com os autores citados, e mostrou também que existe uma relação de causa e efeito entre os fatores que interferem na implantação do BSC, sendo o envolvimento da alta direção o principal fator.

Com base nesta pesquisa, um estudo mais aprofundado sobre os fatores que interferem na implantação de um sistema de gestão baseado no balanced scorecard em instituições governamentais, enfatizando as questões de transição gerencial, podem apresentar fatores não identificados neste trabalho.

Espera-se com esse estudo, contribuir para o processo de implantação de um instrumento de gestão estratégica baseado no balanced scorecard, visando a auxiliar as empresas, principalmente as públicas, a avançarem da formulação para a implantação das estratégias, revertendo, assim, as estatísticas apresentadas no início desse estudo.

\section{REFERÊNCIAS}

BIEKER, T. Sustainability management with the Balanced Scorecard. In: INTERNATIONAL SUMMER ACADEMY ON TECHNOLOGY STUDIES: Urban Infrastructure in Transition: What can we learn from History?, $6^{\text {th }}, 2003$, Austria. Anais eletrônicos... Disponível em: <http://www.ifz. tugraz.at/index_en.php/article/ articleview/331/I/30/>. Acesso em: jan. de 2004. EMBRAPA. Carta do presidente. Dia: 24 de julho de 2003, Brasília: Embrapa, 2003.

EMBRAPA. Departamento de Organização e Desenvolvimento. Descrição do geral do MGE. Brasília: Embrapa, 2002 
EMBRAPA. Modelo de gestão estratégica. Brasília: Embrapa, 2000.

EMBRAPA. Projeto Modelo de Gestão Estratégica: Relatório Gerencial de I999.

EPSTEIN, M.; MANZONI, J. F. Implementing corporate strategy: from tableaux de board to balanced scorecards. In: European Management Journal, v.I6, n.2, abril I998.

FRESNEDA, P. S. V. Estudo de caso: modelo de gestão estratégia da Embrapa. In: FÓRUM BALANCED SCORECARD BRASIL, I., 2002, São Paulo. Anais eletrônicos... São Paulo: Symnetics, 2002. Disponível em: <http://www.symnetics.com.br/artigos/detalhe.asp?id=39>. Acesso em: 03 ago. 2003.

GIL, A. C. Métodos e Técnicas de Pesquisa Social. São Paulo: Atlas, I994.

GOLLO, S.; CASTRO, A. W. V. Gestão estratégica: aplicação na Embrapa. CONGRESSO INTERNACIONAL DE ECONOMIA E GESTÃO DE REDES AGROALIMENTARES, 3., Ribeirão Preto. Anais eletrônicos... Ribeirão Preto: FEA-RP, 200I. Disponível em: <http://www.fearp.usp.br/egna/ Por/anozoor.HTM>. Acesso em: 23 jul. 2003.

GUILHERME, R.; GOLDSZMIDT, B. Uma revisão de literatura dos fatores críticos para a implementação e uso do balanced scorecard. In: ENCONTRO ANUAL DA ASSOCIAÇÃO NACIONAL DOS PROGRAMAS DE PÓS-GRADUAÇÃO EM ADMINISTRAÇÃO, 27º, 2003, São Paulo. Anais... São Paulo: Anpad, 2003. Estudos Organizacionais.

KAPLAN, R.; NORTON, D. A estratégia em ação: balanced scorecard. I4. ed. Rio de Janeiro: Campus, I997.

KAPLAN, R.; NORTON, D. Organização orientada para a estratégia: como as empresas que adotam o balanced scorecard prosperam no novo ambiente de negócios. 6. ed. Rio de Janeiro: Campus, 2000.

KIMURA, H.; SUEN, S. Ferramentas de análise gerencial baseadas em modelos de decisão multicriteriais. RAE eletrônica. São Paulo: FGV-EAESP, v.2, n.I, jan-jun. 2003. Internet. Disponível em: $<$ http://www.rac.com.br/eletronica>. Acesso em: 27 jun. 2003.

MINTZBERG, H.; AHLSTRAND, B.; LAMPEL, J. Safári de estratégia: um roteiro pela selva do planejamento estratégico. Porto Alegre: Bookman, 2000.

NIVEN, P. R. Adapting the balanced scorecard to fit the public and nonprofit sectors. Disponível em: $<$ http://www.balancedscorecard.biz/articles.html>. Acesso em: I8 dez 2003.

OLVE, N.-G.; ROY, J.; WETTER, M. Condutores da performance: um guia prático para o uso do balanced scorecard. Rio de Janeiro: Qualitymark, 200I.

ROEST, P. The golden rules for implementing the Balanced Business Scorecard. In: Information Management \& Computer Security, v.5, n.5, I997.

RUAS, E. B. Criação de indicadores estratégicos para o Instituto de Pesquisas Tecnológicas do Estado de São Paulo S.A - IPT. In: RAE-eletrônica, São Paulo: FGV-EAESP, v.2, n.I, jan-jun/2003. Internet. Disponível em: <http://www.rae.com.br/eletronica/>. Acesso em: 27 jun. 2003.

SCHNEIDERMAN, A. M. Why Balanced scorecards fail. In: Journal of Strategic Performance Measurement, janeiro I999, Edição Especial, p. 6.

SOARES JÚNIOR, H.; PROCHNIK, V. Experiências comparadas de implantação do balanced scorecard no Brasil. Internet. Disponível em: <http://www.ie.ufrj.br/cadeiasprodutivas/download_estrategia_e_gestao.html>. Acesso em: I6 ago 2003.

YIN, R. K. Estudo de caso: planejamento e métodos. 2. ed. Porto Alegre: Bookman, 20oI.

\section{TRAMITAÇÃO}

Submissão: 21/o6/2004

Aprovação: 22/11/2004 
Copyright of Revista de Administração Mackenzie is the property of Universidade Presbiteriana Mackenzie, RAM-Revista de Administracao Mackenzie and its content may not be copied or emailed to multiple sites or posted to a listserv without the copyright holder's express written permission. However, users may print, download, or email articles for individual use. 